\title{
Drained and Undrained Behavior of an Aeolian Sand from Natal, Brazil
}

\author{
P.L. Souza Junior, O.F. Santos Junior, T.B. Fontoura, O. Freitas Neto
}

\begin{abstract}
The behavior of sands subjected to diverse loading conditions has been the object of many studies in recent decades. Constitutive models that are able to simulate the behavior of sands have been developed based on critical state theory. Researchers have shown that the defining parameters of the critical state line (CSL) can be obtained by performing drained and undrained tests on samples with different initial densities. This work aims to verify the drained and undrained behavior of aeolian sand from Natal, Brazil, based on critical state soil mechanics. Drained and undrained tests were performed on samples with initial void ratios equal to 0.7 and 0.8 , which correspond to loose and medium-dense relative densities, respectively. Samples with both void ratios were subjected to confining stresses equal to 50, 100, 200 and $300 \mathrm{kPa}$. The results show that the critical state line can be defined from the drained and undrained tests performed on samples with loose and medium-dense initial relative densities. The parameters from the critical state theory were obtained using projections on the planes $p^{\prime}-q$ and $\ln p^{\prime}-v$. The critical state friction angle is equal to $31.5^{\circ}$, and it is compatible with clean and uniformly graded sands with angular to subangular features and composed mostly of quartz. The obtained $\mathrm{M}, \Gamma$ and $\lambda$ values are equal to $1.26,1.863$ and 0.03 , respectively. The obtained parameters will be used in analyses and numerical simulations of the geotechnical structures built on aeolian dune deposits from the city of Natal, Brazil.
\end{abstract}

Keywords: critical friction angle, critical state, dune sand, loose sand, steady state, triaxial test.

\section{Introduction}

Critical state theory has been the basis for the formulation of constitutive models capable of predicting the behavior of soils subjected to many loading conditions. The critical state is defined as the state eventually reached by the soil during shearing when strength variations and volume variations (in drained cases) or pore-pressure variations (in undrained cases) cease.

The critical state theory was based on tests performed on normal and overconsolidated clays. The mathematical formulations and the parameters from the theory were obtained from the projection of the critical state line plotted on $q-p^{\prime}$ and $v-p$ ' planes. It has been found that this model could also be used on sands. Understanding which elements affect the critical state line in sand is the subject of many studies (Sladen \& Handford, 1987; Chu and Lo, 1993; Riemer \& Seed, 1997; Murthy et al., 2007; Li et al., 2013).

Test results have become essential to the formulation and refinement of constitutive models for sands. The latest research explores the effects of fines content, initial fabric, and grain size distribution on the behavior of the critical state lines and their projections (Li \& Dafalias, 2012; Gao et al., 2013; Rahman \& Lo, 2014; Wei \& Yang, 2019; Woo et al., 2017; Yang \& Luo, 2018). The initial state and drained conditions were not found to affect the positioning of the critical state line (Been et al., 1991; Verdugo \& Ishihara, 1996).

Sands from different regions around the world have been studied and continue to be studied under the critical state soil mechanics framework. Some urban areas from the city of Natal were positioned upon dunes, which are aeolian coastal deposits, consisting of unconsolidated or partially consolidated materials, and mostly made of quartz that is fine to medium in size.

Understanding the geotechnical behavior of these materials and obtaining their critical state parameters is required to perform numerical analyses of the geotechnical structures built on the dune fields from the city of Natal, Brazil, in addition to providing data that can be used in the calibration or refinement of constitutive models of sands with similar features. Furthermore, available research on aeolian sands is still scarce.

The present work aims to investigate the behavior of aeolian sand from the city of Natal, the capital of the State of Rio Grande do Norte in Brazil. Drained and undrained triaxial tests were performed on loose and medium-dense specimens.

Paulo Leite de Souza Junior, M.Sc., Graduate Student, Programa de Pós-Graduação em Engenharia Civil, Universidade Federal do Rio Grande do Norte, RN, Brazil. e-mail: pauloleitesjunior@yahoo.com.br.

Olavo Francisco dos Santos Junior, D.Sc., Full Professor, Programa de Pós-Graduação em Engenharia Civil, Universidade Federal do Rio Grande do Norte, Natal, RN, Brazil. e-mail: olavo.santos@ufrn.edu.br.

Tahyara Barbalho Fontoura, M.Sc., Assistant Professor, Instituto Federal do Rio Grande do Norte. São Paulo do Potengi, RN, Brazil. e-mail: tahyara.barbalho@ifrn.edu.br. Osvaldo de Freitas Neto, D.Sc., Associate Professor, Programa de Pós-Graduação em Engenharia Civil, Universidade Federal do Rio Grande do Norte, Natal, RN, Brazil. e-mail: osvaldocivil@ufrn.edu.br.

Submitted on June 5, 2019; Final Acceptance on March 11, 2020; Discussion open until September 30, 2020.

DOI: $10.28927 /$ SR.432263 


\section{Materials and Methods}

The data discussed in the present work were obtained from triaxial tests performed on sand collected in the main campus of the Federal University of Rio Grande do Norte.

Figure 1 shows the grain size distribution of the soil obtained by sieving. Grading is uniform, and approximately $70 \%$ of the grains are considered to be medium sand.

The soil was classified as poorly graded sand (SP) according to the Unified Soil Classification System, with a fines content below $5 \%$. The soil grains were angular to subangular. The physical parameters of the Natal dune sand were obtained by Fontoura (2015) and are presented in Table 1 .

Specimens were prepared by tamping moist sand in four layers into a metallic split mold $100 \mathrm{~mm}$ in height and $50 \mathrm{~mm}$ in diameter. The soil water content was $6 \%$. The specimens were compacted to reach two conditions: (1) the maximum void ratio, corresponding to the loosest density state; and (2) a relative density of $47 \%$, corresponding to a medium-dense state. Each specimen was tested under effective confining stresses of 50,100, 200 and $300 \mathrm{kPa}$ in both drained and undrained conditions, totaling 16 tests.

The removal of the metallic mold after the preparation of the specimens was the main difficulty in the study of sand, especially in the softest state. The tests performed by Fontoura (2015) showed that a moisture content of $6 \%$ was sufficient to give the soil an "apparent cohesion" sufficient for modeling and demolding the specimens. Nevertheless, cases of specimen disaggregation occurred during demolding, requiring the specimen assembly procedure to be repeated in the triaxial chamber. Specimens were subjected to percolation, and increases in back pressure were applied to ensure saturation. Back pressure stages were applied at

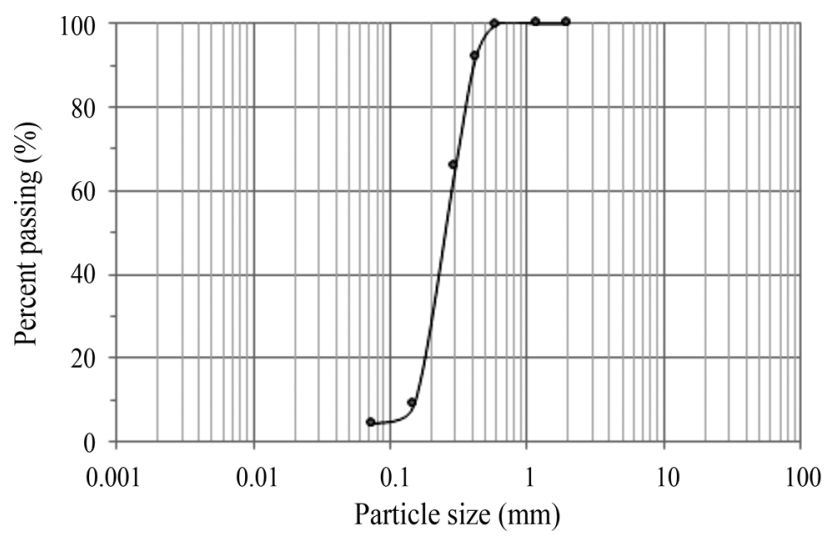

Figure 1 - Grain size distribution of the Natal dune sand.

Table 1 - Physical parameters of the Natal dune sand.

\begin{tabular}{lccccc}
\hline$D_{50}(\mathrm{~mm})$ & $D_{10}(\mathrm{~mm})$ & $C_{u}$ & $e_{\min }$ & $e_{\max }$ & $G_{s}$ \\
\hline 0.25 & 0.15 & 1.86 & 0.590 & 0.800 & 2.660 \\
\hline
\end{tabular}

$50 \mathrm{kPa}$ intervals until the $\mathrm{B}$ parameter reached 0.95 or higher. This value was usually reached after the application of 6 stages, corresponding to a total back pressure equal to $300 \mathrm{kPa}$.

After saturation, the specimens were isotropically consolidated until the desired confining stress was reached. During consolidation, the volume changes caused by increases in the confining pressure were measured. The void ratio was calculated from the sample size, the sand mass inserted into the mold and the water content used in the sample preparation $(6 \%)$. The void ratio after consolidation was calculated taking into account the sample volume variation that occurred at the time of consolidation. The initial (after molding) and final (after consolidation) void ratios are presented in Table 4.

Deformation was controlled during shearing, with a constant axial displacement rate equal to $0.20 \mathrm{~mm} / \mathrm{min}$ in undrained tests and $0.06 \mathrm{~mm} / \mathrm{min}$ in drained tests. These rates were obtained based on the ASTM standard. The strain rate is a function of the consolidation time. For the Natal sand, consolidation is virtually instantaneous with the application of stress. This would result in a very high strain rate. The values chosen were much lower than those indicated in the calculations. Thus, the equalization of pore pressures in the undrained tests and the inhibition of pore pressures in the drained tests were ensured.

\section{Results and Discussion}

\subsection{Stress-strain curves}

The results from drained tests with loose and medium-dense sand specimens are shown in Figs. 2 and 3, respectively.

In tests on the loose sand (Fig. 2), the deviatoric stress increases with strain and reaches a maximum value after $15 \%$ of axial deformation. After that, the deviatoric stress remains constant. This is also evident in the $q^{\prime} / p^{\prime} v s$. axial strain curves. Regarding volumetric behavior, compressive volumetric strains were observed for all confining stresses. It is believed that volumetric compression tends to reach a constant value in all cases after reaching a strain equal to $20 \%$. The curves representing $q-p$ ' ratios against strain virtually overlap and reach a constant value at the end of the tests.

In tests with medium-dense specimens (Fig. 3), deviatoric stress reaches a maximum value after small strains and stays constant until the end of testing. Regarding volumetric behavior, tests with initial confining stress equal to $50 \mathrm{kPa}$ and $100 \mathrm{kPa}$ exhibit an initial compression followed by a volumetric expansion until the end of testing. Volume changes in the test with confining pressure equal to $200 \mathrm{kPa}$ behave like those in the previous conditions but are less significant, and its curve is closer to the axis of zero volume variation. The curve related to the $300 \mathrm{kPa}$ confining pressure shows compression at the beginning of testing, which 

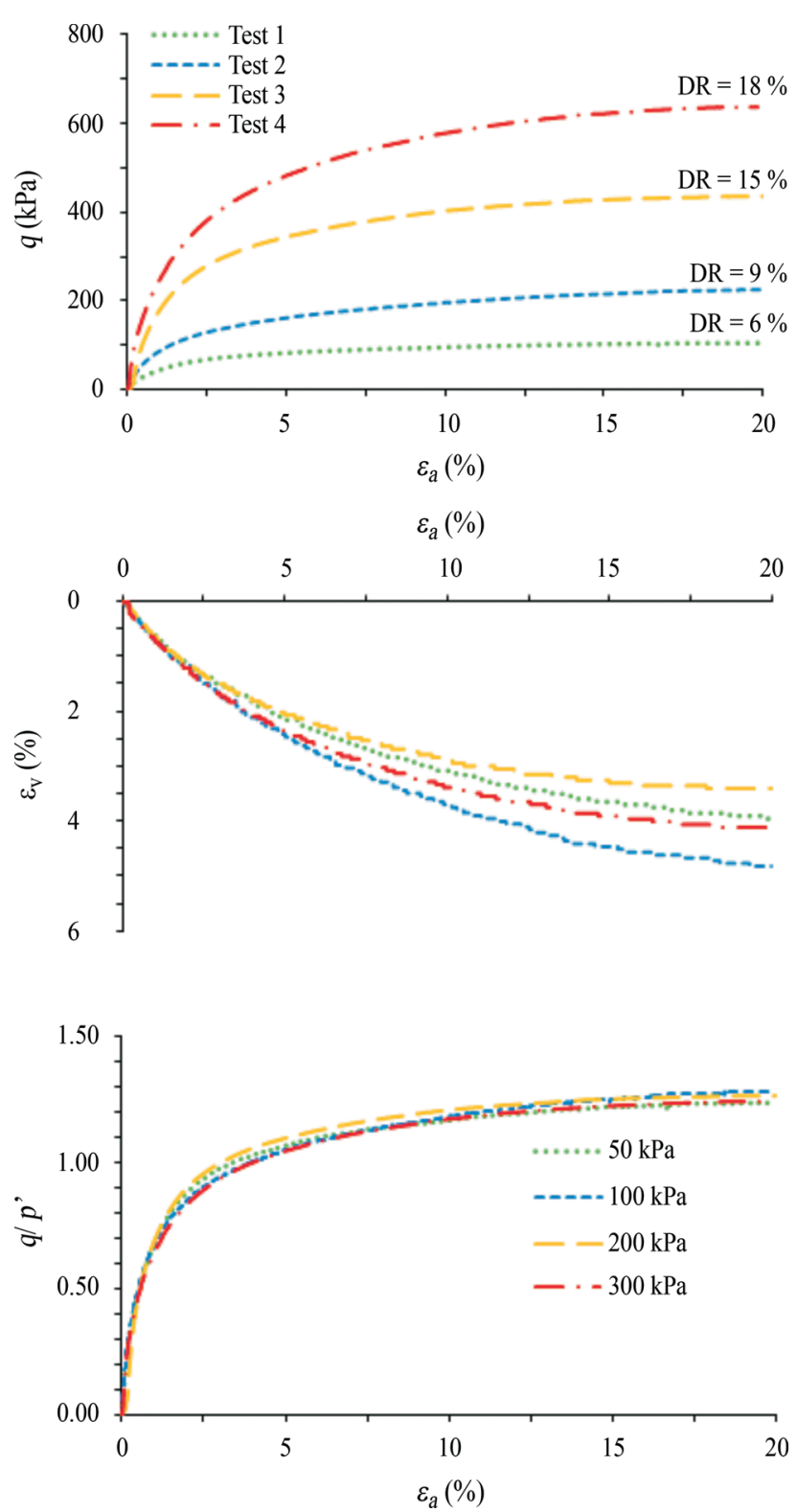

Figure 2 - Drained tests on loose sand.

is kept constant with strain. A slight expansion trend can be observed near the end of testing. Curves showing $q$ - $p$ ' ratios seemingly reach a constant value at the end of the test.

Figures 4 and 5 show the undrained behavior of loose and medium-dense specimens.

Loose sand specimens under undrained conditions exhibit a deviatoric peak stress under small strains (Fig. 4). After the peak, a small decrease in strength occurs. This behavior can be observed for all confining stresses. Pore pressure changes are positive in all tests. The pore pressure increases as the confining stress increases. Curves with the ratio between stresses $\left(q^{\prime} / p^{\prime}\right)$ overlap and reach similar values at the end of testing. The maximum value of $q^{\prime} / p^{\prime}$ reached in undrained tests was 1.20. These values are lower than those obtained in drained tests (1.28).
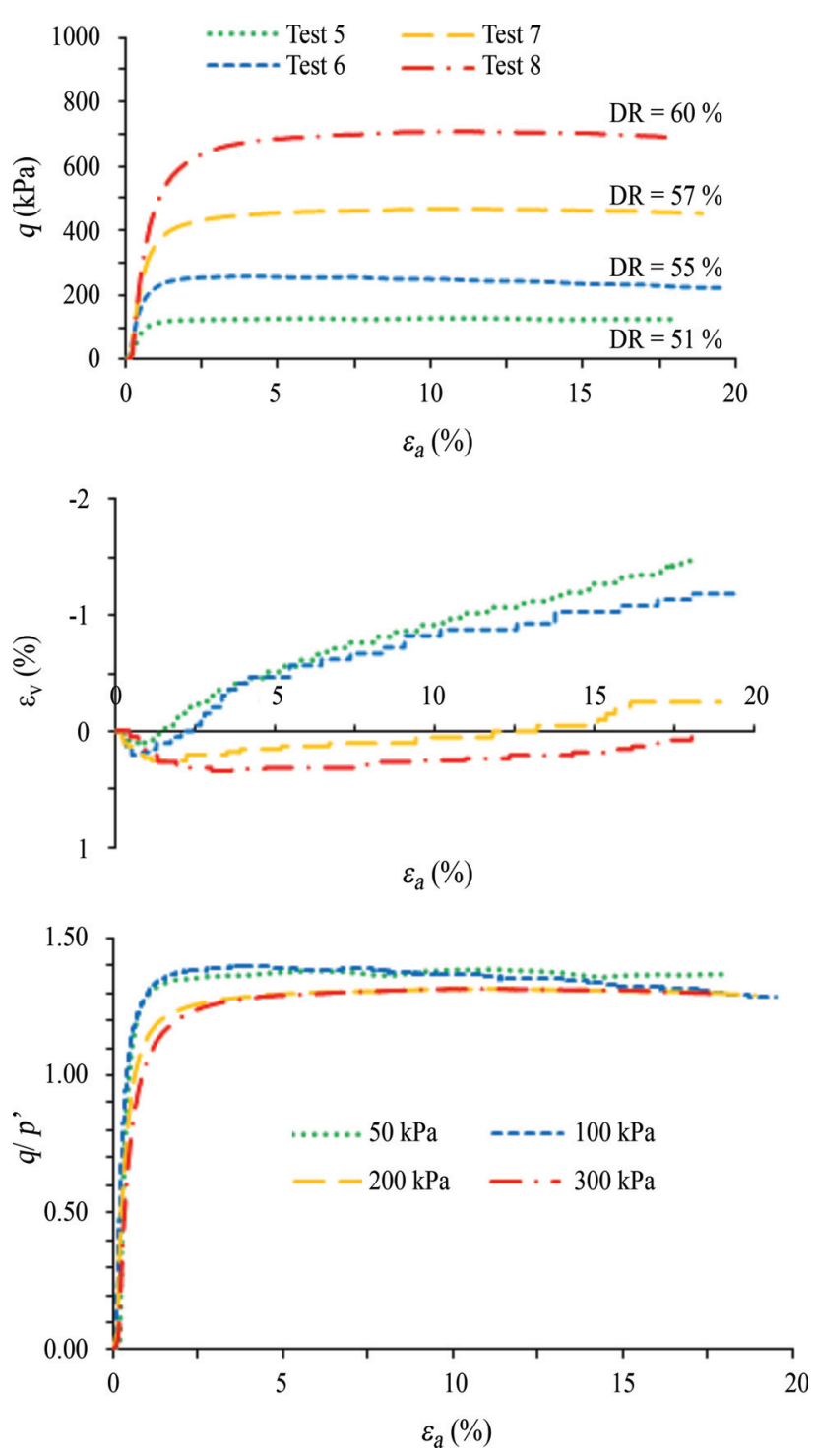

Figure 3 - Drained tests on medium-dense sand.

In tests with medium-dense sand, hardening behavior occurs during all initial confining stresses. The strength continues to increase even after the axial strain reaches $20 \%$. Porewater pressure changes are positive at small axial strains and start decreasing and becoming negative at the end of the tests. All curves representing $q / p$ ' ratios virtually overlap, reaching a maximum value at small strains and staying constant until the end of the test.

\subsection{Critical state line}

Figure 6 shows the projections from the CSL in the $q$ - $p$ ' plane using the final points obtained from the tests. The value of $\mathrm{M}$ is equal to 1.26 , which corresponds to a critical state friction angle equal to $31.5^{\circ}$.

A literature review shows a recurrent discussion on the similarity between the critical state and steady state, as well as the uniqueness of the critical state line (or steady 
Souza Junior et al.
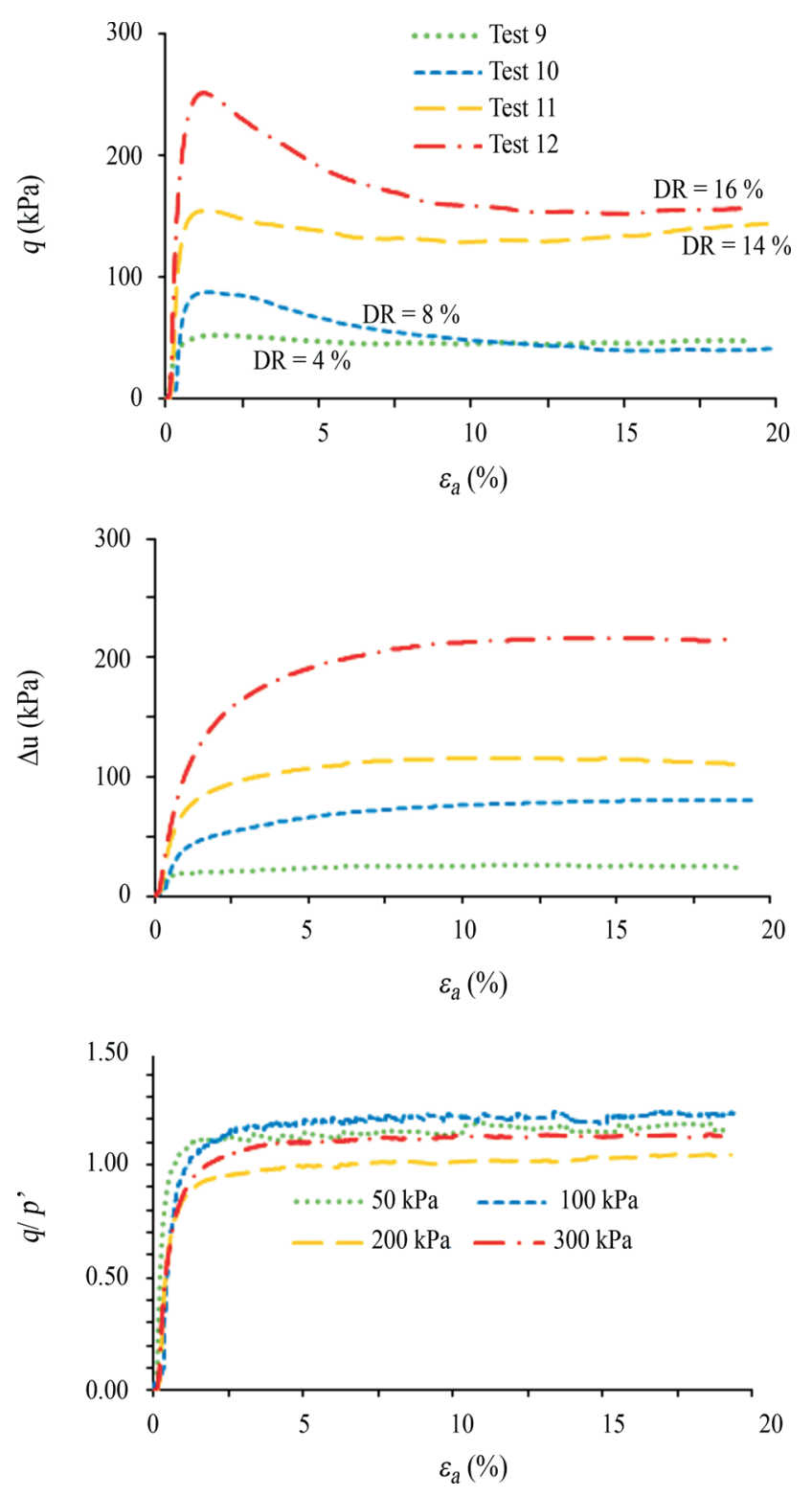

Figure 4 - Undrained tests on loose sand.

state line). In this paper, it is assumed that the critical state and steady state are equivalent and that there is a single critical state line, since research has shown evidence that supports this idea (Mooney et al., 1988; Been et al., 1991; Kang et al., 2019).

Figure 7 shows the curves obtained in the $v$ - $p^{\prime}$ plane. Only one of the undrained tests in loose sand was used in this plot. The data from the other tests appear scattered when plotted on these planes, possibly because volume changes during the saturation process could not be reliably measured.

After analyzing the data from the drained and undrained tests with aeolian sand from Natal under different initial density conditions, the parameters from the critical state theory were obtained and are shown in Table 2.
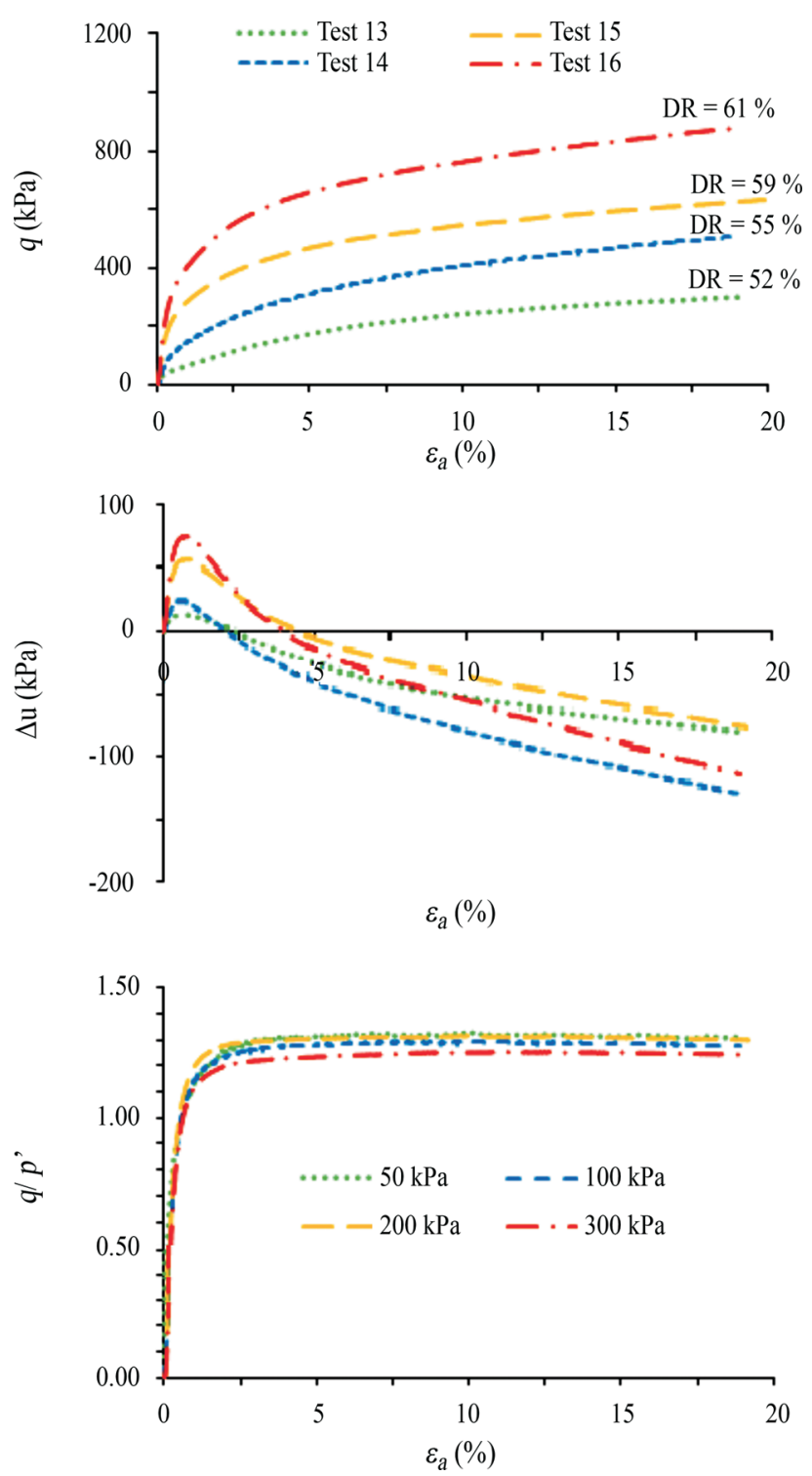

Figure 5 - Undrained tests on medium-dense sand.

\subsection{Critical state parameters of aeolian sand from Na- tal, Brazil}

The results are compatible with those presented in the literature related to clean, uniformly graded quartz sands, as shown in Table 3.

All sands shown in Table 3 are characterized by grains with angular to subangular shapes. The Ottawa sand is the exception because it is composed of rounded grains, which may help explain its lower critical state angle value when compared to the critical state angle values of the other samples.

\subsection{Stress paths}

Figure 8 shows the stress paths from the tests with loose and medium-dense sands plotted on $p-q$ ' diagrams. The stress paths from the undrained tests in loose speci- 


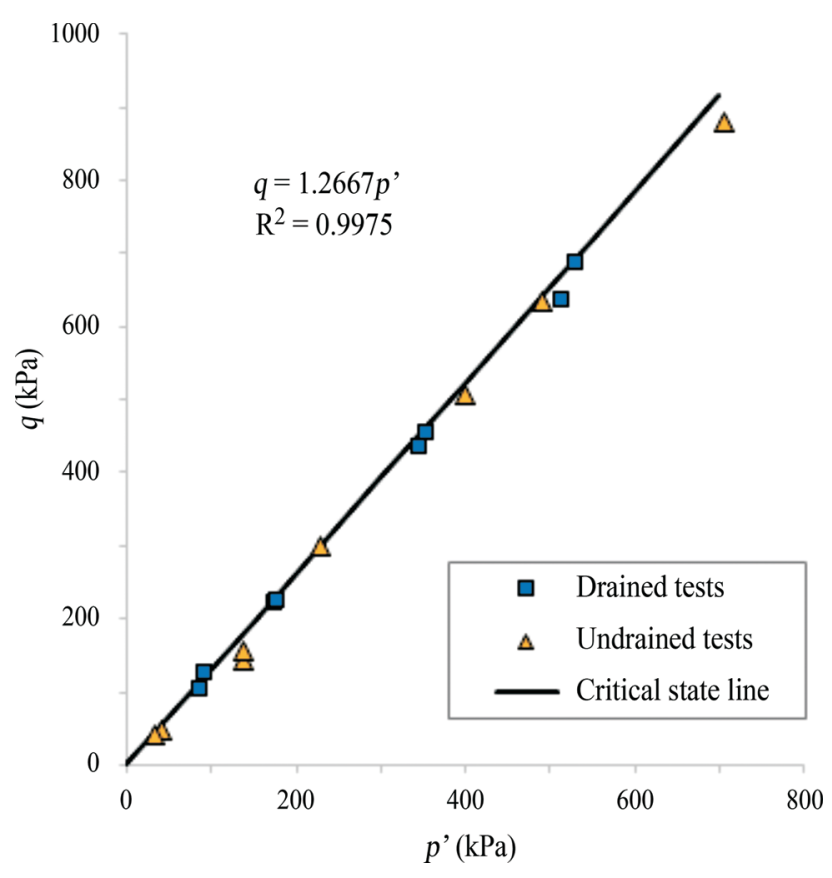

Figure 6 - Critical state line in the $q$ - p' plane.

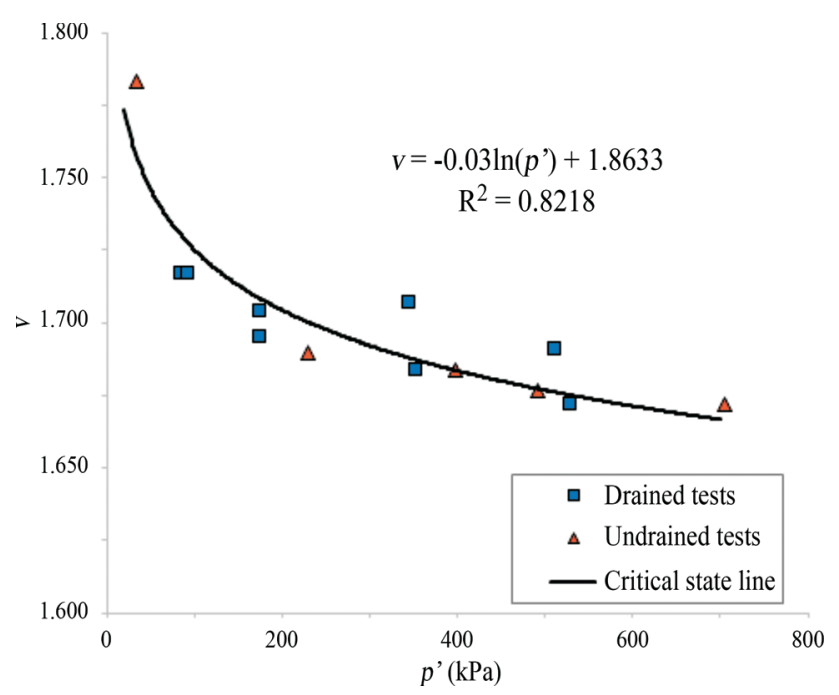

Figure 7 - Critical state line in the $v$ - p' plane.

Table 2 - Critical state parameters of the Natal dune sand.

\begin{tabular}{lccc}
\hline $\mathrm{M}$ & $\phi_{c s}\left({ }^{\circ}\right)$ & $\Gamma$ & $\lambda$ \\
\hline 1.26 & 31.5 & 1.863 & 0.03 \\
\hline
\end{tabular}

Table 4 - State parameters of all tests.

\begin{tabular}{llcccc}
\hline Test & $\begin{array}{c}\text { Drainage } \\
\text { condition }\end{array}$ & $\begin{array}{c}\text { Confining } \\
\text { pressure }\end{array}$ & $e_{0}$ & $e_{c}$ & $\psi$ \\
\hline 1 & Drained & 50 & 0.8 & 0.788 & 0.042 \\
2 & & 100 & 0.8 & 0.782 & 0.057 \\
3 & 200 & 0.8 & 0.768 & 0.064 \\
4 & & 300 & 0.8 & 0.763 & 0.071 \\
5 & Drained & 50 & 0.7 & 0.692 & -0.054 \\
6 & & 100 & 0.7 & 0.684 & -0.041 \\
7 & & 200 & 0.7 & 0.680 & -0.024 \\
8 & & 300 & 0.7 & 0.673 & -0.019 \\
9 & Undrained & 50 & 0.8 & 0.791 & 0.045 \\
10 & & 100 & 0.8 & 0.783 & 0.058 \\
11 & & 200 & 0.8 & 0.771 & 0.067 \\
12 & & 300 & 0.8 & 0.766 & 0.074 \\
13 & Undrained & 50 & 0.7 & 0.690 & -0.056 \\
14 & & 100 & 0.7 & 0.684 & -0.041 \\
15 & & 200 & 0.7 & 0.677 & -0.027 \\
16 & & 300 & 0.7 & 0.672 & -0.020 \\
\hline
\end{tabular}

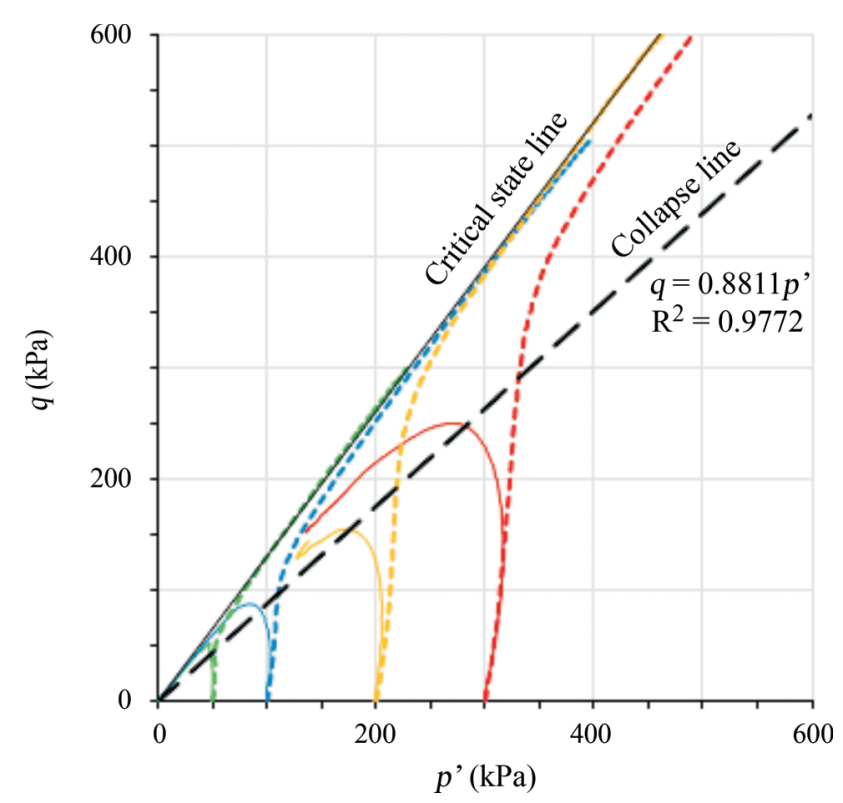

Figure 8 - Undrained stress paths for shear plotted on $q$ - $p$ ' diagrams for loose and medium dense sand.

Table 3 - Critical state parameters of the sands.

\begin{tabular}{lccccc}
\hline Sand & $\mathrm{M}$ & $\phi_{c s}\left({ }^{\circ}\right)$ & $\Gamma^{*}$ & $\lambda$ & Reference \\
\hline Toyoura & 1.28 & 31.8 & 0.934 & 0.019 & (Verdugo \& Ishihara, 1996) \\
Ottawa & 1.20 & 30.2 & 0.780 & 0.081 & (Murthy et al., 2007) \\
Coimbra & 1.29 & 32.0 & 0.976 & 0.04 & (Abreu, 2012) \\
Hostun & 1.26 & 31.5 & $1.00^{* *}$ & 0.07 & (Azeiteiro et al., 2017) \\
\hline
\end{tabular}

Note: *Obtained in the $e-p^{\prime}$ plane. $* *$ Adopted as being equal to $e_{\max }$. 


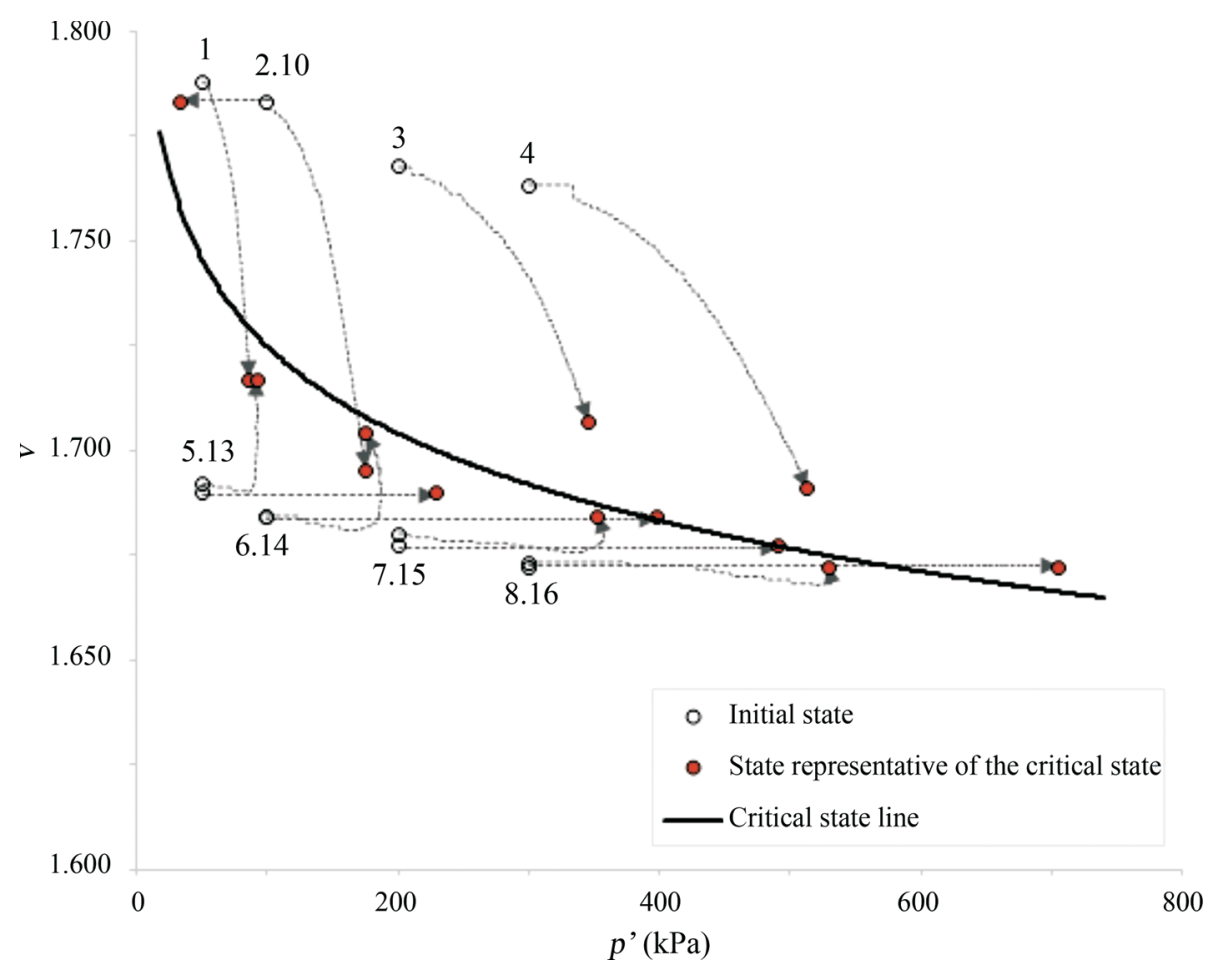

Figure 9 - Drained and undrained paths in the $v$ - p' plane.

mens are located to the left of the paths from the drained tests because positive porewater pressure was generated during shearing. This behavior is associated with the liquefaction phenomenon during static loading. A single liquefaction (or collapse) line is also presented in Fig. 8.

In the drained tests, the compressive behavior of loose sands can be observed in all confining stresses. The paths from medium dense sands exhibit dilation and compression behaviors. Paths from tests with confining pressures equal to $200 \mathrm{kPa}$ and $300 \mathrm{kPa}$ show compressive behavior, with slight dilation at the end of the test, and are presented as near horizontal lines. This finding suggests that shearing occurred in a state that was close to the critical state, as implied by the stress-strain and volume-strain plots.

In the undrained tests using medium-dense samples, the paths move to the right until they reach the critical state line. This behavior is typical of points located below the critical state line, under which negative porewater pressure occurs. In loose specimens, initial points are located above the critical state line; positive porewater pressures appear during shearing, producing a decrease in the effective average stress and causing the paths to move to the left toward the critical state line.

The paths from tests using confining pressure equal to $300 \mathrm{kPa}$ show a peculiar behavior. In drained tests, only compressive behavior was observed. It was expected that its undrained counterpart would exhibit positive backpressure changes, which did not occur. Despite this behavior, it is possible to observe in Fig. 9 that the undrained path would necessarily move toward the critical state line; therefore, the undrained path would have to exhibit negative porewater pressure, as actually observed in the tests.

Both paths overlap during the beginning of the tests and tend to diverge at the end of the tests. This dilation trend in the drained test is associated with the difficulties in representing the actual behavior of sands due to the high level of deformation in the specimens.

\section{Conclusions}

The drained and undrained behavior of the aeolian sand from Natal, Brazil, has been studied through triaxial tests using different confining stresses and void ratios. The test results were analyzed in the critical state framework.

Specimens with an initial void ratio equal to 0.8 were located above the critical state line and exhibited compressive behavior; moreover, medium-dense specimens showed either dilation or compression, depending on the confining stress.

Specimens prepared with medium-dense sand and subjected to a confining stress equal to $300 \mathrm{kPa}$ only exhibited compressive behavior.

The critical state line was defined from drained and undrained tests with loose and medium-dense specimens for an average confining stress level of almost $700 \mathrm{kPa}$.

Stress paths from the drained and undrained tests on loose and medium-dense specimens apparently converged to the critical state line, which validates the results presented. 
The critical state theory parameters were obtained from projections on $p^{\prime}-q$ and $v-\ln p^{\prime}$ diagrams. The results obtained for aeolian sand are compatible with the values found in the literature when compared to sands of alluvial and marine origin with similar physical properties.

The critical state friction angle is equal to $31.5^{\circ}$, and it is compatible with clean, uniformly graded sands with angular to subangular shapes that are composed mostly of quartz.

The results from this research can be used as a reliable source of data for the calibration of constitutive models based on critical state theory; in addition, they can be used for numerical analyses involving the mechanical behavior of the aeolian Natal sand, including its susceptibility to liquefaction.

\section{Acknowledgments}

The authors acknowledge the Coordination for the Improvement of Higher Education (CAPES) and the National Council for Scientific and Technological Development (CNPq) for their financial support.

\section{References}

Abreu, E.J.A. (2012). Study of Liquefaction Conditions of Coimbra Sand in Static and Cyclic Triaxial. Master Thesis, Department of Civil Engineering, University of Porto, Porto, 119 p. (In Portuguese).

Azeiteiro, R.J.N.; Coelho, P.A.L.; Taborda, D.M.G. \& Grazina, J.C.D. (2017). Critical state-based interpretation of the monotonic behavior of Hostun sand. Journal of Geotechnical and Geoenvironmental Engineering, 143(5):040170041-0401700414. https://doi.org/10.1061/(ASCE)GT.1943-5606.000165 9

Been, K.; Jefferies, M.G. \& Hachey, J. (1991). The critical state of sands. Géotechnique, 41(3):365-381. https://doi.org/10.1680/geot.1991.41.3.365

Chu, J.; \& Lo, S.C.R. (1993). On the measurement of critical state parameter of dense granular soils. Geotechnical Testing Journal, 16(1):27-35. https://doi.org/10.1061/(ASCE)1090-0241(2006)132:5 (591)

Fontoura, T.B. (2015). Stress-Strain Behavior and Shear Strength of Artificially Cemented Dune Sand. Master Thesis, Postgraduate Program in Civil Engineering, Federal University of Rio Grande do Norte, Natal, 168 p. (In Portuguese).

Gao, Z.; Zhao, J.; Li, X.S. \& Dafalias, Y.F. (2013). A critical state sand plasticity model accounting for fabric evolution. International Journal for Numerical and Analytical Methods in Geomechanics, 38(4):370-390. https://doi.org/10.1002/nag.2211

Kang, X.; Xia, Z.; Chen, R.; Ge, L. \& Liu, X. (2019). The critical state and steady state of sand: A literature review. Marine Georesources \& Geotechnology,
37(9):1105-1118. https://doi.org/10.1080/1064119X.2018.1534294

Li, X.S. \& Dafalias, Y.F. (2012). Anisotropic critical state theory: Role of fabric. Journal of Engineering Mechanics, 138(3):263-275. https://doi.org/10.1061/(ASCE)EM.1943-7889.0000324

Li, G.; Ovalle, C.; Dano, C. \& Hicher, P.Y. (2013). Influence of Grain Size Distribution on Critical State of Granular Materials. Springer Series in Geomechanics and Geoengineering, Berlin, pp. 207-210. https://doi.org/10.1007/978-3-642-32814-5_25

Mooney, M.A.; Finno, R.j. \& Viggiani, M.G. (1988). A unique critical state for sand? Journal of Geotechnical and Geoenvironmental Engineering, 124(11):11001108 . https://doi.org/10.1061/(ASCE)1090-0241(2000)126:1 (97)

Murthy, T.G.; Loukidis, D.; Carraro, J.A.H.; Prezzi, M. \& Salgado, R. (2007). Undrained monotonic response of clean and silty sands. Géotechnique, 57(3):273-288. https://doi.org/10.1680/geot.2007.57.3.273

Rahman, M.M. \& Lo, S. R. (2014). Undrained behavior of sand-fines mixtures and their state parameter. Journal of Geotechnical and Geoenvironmental Engineering, 140(7):040140361-0401403612.

https://doi.org/10.1061/(ASCE)GT.1943-5606.0001115

Riemer, M.F. \& Seed, R.B. (1997). Factors affecting apparent position of steady-state line. Journal of Geotechnical and Geoenvironmental Engineering, 123(3):281-288. https://doi.org/10.1061/(ASCE)1090-0241(1997)123:3( 281)

Sladen, J.A. \& Handford, G. (1987). A potential systematic error in laboratory testing of very loose sands. Canadian Geotechnical Journal, 24(1987):462-466. https://doi.org/10.1139/t87-058

Verdugo, R. \& Ishihara, K. (1996). The steady state of sandy soils. Soils and Foundations, 36(2):81-91. https://doi.org/10.3208/sandf.36.2_81

Wei, X. \& Yang, J. (2019). A critical state constitutive model for clean and silty sand. Acta Geotechnica, 14(2):1-17. https://doi.org/10.1007/s11440-018-0675-0

Woo, S.I.; Seo, H. \& Kim, J. (2017). Critical-state-based Mohr-Coulomb plasticity model for sands. Computers and Geotechnics, 92(1):179-185. https://doi.org/10.1016/j.compgeo.2017.08.001

Yang, J. \& Luo, X.D. (2018). The critical state friction angle of granular materials: Does it depend on grading? Acta Geotechnica, 13(3):535-547. https://doi.org/10.1007/s11440-017-0581-X

\section{List of Symbols}

$p^{\prime}:$ mean effective stress

$q$ : deviatoric stress

$v$ : specific volume 
$D_{50}$ : mean grain size

$D_{10}$ : effective grain size

$D R$ : relative density

$C_{\mathrm{u}}$ : uniformity coefficient

$e_{\text {min }}:$ minimum void ratio

$e_{\text {max }}:$ maximum void ratio

$e_{0}$ : void ratio at molding

$e_{c}$ : void ratio after consolidation
$G_{s}$ : specific gravity

$\psi:$ state parameter

M: slope of critical state line on $q$ - p' plane

$\Gamma, \lambda$ : fitting parameters for the critical state line equation

$\phi_{c s}$ : friction angle at critical state

$\varepsilon_{a}:$ axial strain

$\varepsilon_{v}$ : volumetric strain

$\Delta \mathrm{u}$ : pore water pressure variation 